\title{
ROLE OF SONOGRAPHIC IMAGING FINDINGS IN EVALUATION OF CASES PRESENTING WITH HISTORY OF BLUNT ABDOMINAL TRAUMA IN UCMS-TH
}

Sanju Rawal, ${ }^{1}$ Sadhan Mukhi ${ }^{1}$

\section{ABSTRACT}

\section{INTRODUCTION}

Physical examination is often unreliable. Computed tomography scan is costly, time consuming, requires injection of contrast, exposure to radiation and patient transport thereby limiting its use. With the usage of sonography, it is possible to evaluate and help in the management of patients with blunt abdominal trauma. The proposed study enables sonographic technique in assessing and accurately detecting the presence of free fluid and to pin point the injured organ, thereby helping the clinicians and surgeons in appropriate management.

\section{MATERIAL AND METHODS}

Our study was cross sectional conducted on UCMS-TH, Bhairahawa, Nepal. Total 150 cases with history of blunt abdominal trauma were included and scanned by GE LOGIQ6 PRO ultrasound scanner for the duration of one year.

\section{RESULTS}

A total of 150 patients were evaluated out of which 121 were males and 29 females. Free fluid was detected in total 112 cases (74.66\%) out of which with most common injured solid organs were liver and spleen in total 31 cases $(20.7 \%)$ each, which were further confirmed on CT scan.

\section{CONCLUSION}

Ultrasonography is easy to perform, quick, cost effective and is highly sensitive in detecting free fluid and solid organ injuries however insignificant in patients with bowel or mesenteric injuries in cases of blunt abdominal trauma and demand CT scan.

KEYWORDS Blunt abdominal trauma, Computed tomography, Ultrasonography.

1. Department of Radiology, Universal College of Medical Sciences, Bhairahawa, Nepal

DOI: http//doi.org/10.3126/jucms.v8i02.34243

\author{
For Correspondence \\ Dr. Sanju Rawal \\ Universal college of Medical sciences \\ Bhairahawa, Nepal \\ Email: sanjurawalchhetri1983@gmail.com
}




\section{INTRODUCTION}

Today the most common cause of blunt abdominal trauma is motor vehicular accidents, blows and kicks over abdomen, fall from height, fall of heavy objects over abdomen. Physical examination is often unreliable especially when there is associated head injury, spinal cord injury, or drug ingestion and intra-abdominal injuries may be missed in 16 to $45 \%$ of patients. ${ }^{1-3}$ Computed tomography scan is non-invasive and accurate but costly, time consuming, requires injection of contrast, exposure to radiation and patient transport thereby limiting its use With the development of sonography it is possible to evaluate and help in the management of patients with blunt abdominal trauma.

In recent years, abdominal ultrasonography has taken quantum leaps in its utility, accuracy and acceptance by the clinical community as it is easy to perform, quick, costeffective, non-invasive, no ionizing radiation or toxic contrast material is needed and can be repeated as often as required. ${ }^{6-8}$

The proposed study enables sonographic technique in assessing and accurately detecting the presence of free fluid and to pin point the injured organ, thereby helping the clinicians and surgeons in prompt appropriate management.

\section{MATERIAL AND METHODS}

Our study was cross sectional and was conducted in Department of Radio-diagnosis, Universal College of Medical Science-Teaching Hospital (UCMS-TH), Bhairahawa, Nepal.

All the patients who came to Emergency/OPD of Radio diagnosis Department with blunt abdominal trauma irrespective of age and sex were included and all the patients who had penetrating abdominal injuries and not given consent were excluded.

Study population and sample size was determined as follow: $\mathrm{n}=(1.96)^{2} \times 0.10 \times 0.93 /(0.0025=150$ where, $\mathrm{n}=$ sample size, $\mathrm{z}=$ critical value $=1.96, \mathrm{P}=$ prevalence of disease $=10.5 \%, \mathrm{Q}=$ without disease (1-P), $\mathrm{D}=$ allowance error $(5 \%)$

The duration of study was of approximately one year (November 2018-October 2019). Equipment used for the procedure was GE LOGIQ6 PRO ultrasound scanner. All the data were fed to MS EXCEL (Microsoft office 2007) and then analysed by statistical package for social service (SPSS) for window version SPSS 22, Inc. Chicago, IL. Ethical approval was taken from Institutional Review Committee with registration number UCMS/IRC/054/19 history of blunt abdominal trauma. Out of 150 patients evaluated sonographically, 121 were males and 29 were females. Thus, an overall male predominance of $80.7 \%$ was noted. In our study, the youngest patient was of age two years, and eldest of 85 years. The peak incidence of $25.3 \%$ was present in the second decade and a second peak of $24.7 \%$ in the third decade of life.

Majority of the cases of blunt abdominal trauma was due to road traffic accidents in 91 cases $(60.6 \%)$ and history of fall in 34 cases $(22.7 \%)$. The most common clinical presentation was pain and guarding/rigidity in $144(96 \%)$ and 21 cases (14\%) respectively.

Free fluid was detected in total 112 cases $(74.66 \%)$ with most common injured solid organs were liver and spleen in total 31 $(20.7 \%)$ cases each as depicted in Table 1 . All the cases with detection of free fluid were advised CT scan, 110 cases performed CT scan. Two patients did not perform CT scan due to lack of financial expenses and other factors.

\section{Table 1. Types of injuries}

\begin{tabular}{lcc}
\hline Types of injuries & $\begin{array}{c}\text { No. of cases } \\
\text { (Total=150) }\end{array}$ & Percentage (\%) \\
\hline Free fluid / hemoperitoneum & 112 & 74.66 \\
Liver injury & 31 & 20.7 \\
Spleen injury & 31 & 20.7 \\
Kidney injury & 3 & 2 \\
\hline
\end{tabular}

The most common pattern of injuries detected on patients of splenic injuries was laceration in total number of 27 cases whereas liver hematoma /contusion was detected in total 27 number of cases out of all the patients with liver injuries. Free fluid was detected in all the solid organ injuries.

While ultrasonography was quite sensitive for solid organ injuries however all the bowel and mesentery/omentum injuries was missed on ultrasonography. One case each of liver and splenic laceration was missed on ultrasonography which was further detected on CT scan as depicted in Table 2 below.

\section{Table 2. CT abdomen/pelvis findings missed on USG}

\begin{tabular}{lcc}
\hline Organs injured & No. of cases & Percentage (\%) \\
\hline Mesentry/omentum injury & 7 & 100 \\
Bowel injury & 22 & 100 \\
Liver laceration & 1 & 3.1 \\
Spleen laceration & 1 & 3.1 \\
\hline
\end{tabular}

\section{RESULTS}

A total of 150 patients were evaluated sonographically with a 


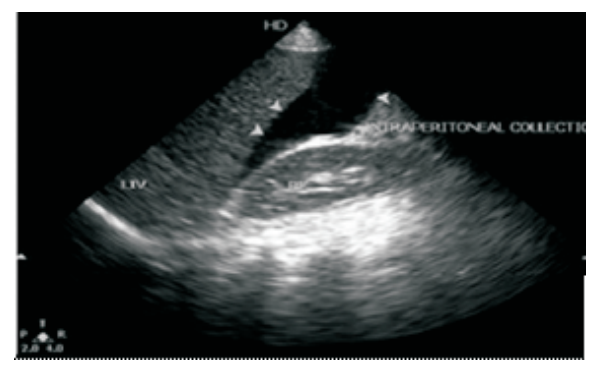

Figure 1. Free fluid/ hemoperitoneum

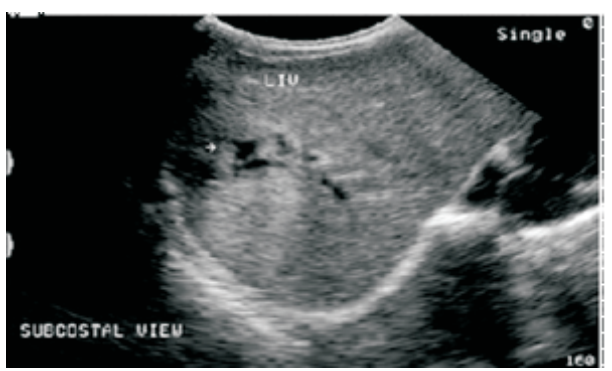

Figure 2. Liver laceration/hematoma

\section{DISCUSSION}

The accuracy of ultrasonography in detecting free fluid on patients with history of blunt abdominal trauma was almost $100 \%$. Out of 112 cases that were advised 110 cases underwent $\mathrm{CT}$ scan with free fluid being present in all of the cases. On CT scan 96 cases (64\%) had significant organ injuries. Whereas on ultrasonography significant organ injuries was present in 65 cases $(43.33 \%)$, however 47 cases $(31.33 \%)$ of free fluid could not be established on ultrasonography and 14 cases $(9 \%)$ cause of free fluid could not be established even on CT scan.

Out of 31 cases of splenic injury and liver injury, splenic laceration and liver hematoma/contusion was the most common pattern of injury present in 27 cases $(87.1 \%)$ each respectively on ultrasonography. In our study three cases had renal injuries with free fluid. All the patients of renal injury had clinical features of haematuria. One case of liver and splenic injury each was missed on ultrasonography which was later detected on $\mathrm{CT}$.

Our findings were very much similar to the study conducted by Rothlin MA, et al ${ }^{9}$ and they found the ultrasonography to be sensitive in almost up to $98 \%$ of the total 312 cases for the detection of free fluid. Luks FI, et $\mathrm{al}^{10}$ in their study detected free fluid in 116 cases with liver and splenic injury being the most common solid organ injury with 44 and 08 cases each, which was similar to our findings. Similarly, in a study conducted by Ming Liu et $\mathrm{al}^{11}$ and Mu Shun Huang et $\mathrm{al}^{12}$ the most common finding was of presence of free fluid (55 and 49 cases respectively) followed by splenic and liver injury as the common solid organ injuries.

Rothlin MA, et $\mathrm{al}^{9} \mathrm{R}$ Grussner et $\mathrm{al}^{13}$ and Akio Kimura et $\mathrm{al}^{14}$ also concluded free fluid being the most common finding in patients with history of blunt abdominal trauma in their study with liver, spleen and kidney the most common solid organ injuries in patient with history of blunt abdominal trauma.

Limitation of our study as with previous studies was inability to detect hollow viscus and mesenteric injuries most of all were missed thus limiting the use of sonography in suspected hollow viscus injuries and warrants CT scan in evaluation of patients with history of blunt abdominal trauma. Technical difficulties during examination also had a role in the evaluation as subcutaneous emphysema, excessive bowel gas leading to negative or false positive outcome.

\section{CONCLUSION}

The detection of an intra-abdominal injury is a frequent diagnostic problem in multiple injured patients. Delay in diagnosis and treatment of abdominal injuries substantially increase morbidity and mortality in trauma patients due to bleeding from solid organ or vascular injury, or infection from perforation of a hollow viscus. Physical examination is often unreliable especially when there is associated head injury, spinal cord injury, or drug ingestion and intra-abdominal injuries may be missed.

In recent years abdominal US has taken quantum leaps in its utility, accuracy and acceptance by the clinical community as it is easy to perform, quick, cost effective, non-invasive, no ionizing radiation or toxic contrast material is needed and can be repeated as often as required. US along with CT (Noninvasive and accurate) is highly effective as equivalent to diagnostic peritoneal lavage (DPL) in patients with blunt abdominal trauma unstable cases.

Ultrasonography is highly sensitive for detection of free fluid and also for majority of solid organ injuries and may help in decreasing the mortality of blunt abdominal trauma cases by aiding in prompt surgical management.

\section{REFERENCES}

1 Peitzman AB, Makaroun MS, Slasky BS, Ritter P. Prospective study of computed tomography in initial management of blunt abdominal trauma. J Trauma. 1986;26(7):585-91.

2 Bagwell CE, Ferguson WW. Blunt abdominal trauma: Exploratory laparotomy or peritoneal lavage. Am J Surg. 1980;140:368-73.

3 Lingawi SS, Buckley AR. Focused abdominal US in patients with trauma. Radiology 2000;217:426-29. 
4 Richards JR, Derlet RW. Computed tomography for blunt abdominal trauma in the ED: A prospective study. Am J Emerg Med. 1998;16:338-42.

5 Richards JR, Knopf NA, Wang L, McGahan JP. Blunt abdominal trauma in children: Evaluation with emergency US Radiol. 2002;222:749-54

6 Healey MA, Simons RK, Winchell RJ. A Prospective evaluation of abdominal ultrasound in blunt trauma: Is it useful? J Trauma. 1996;40:875-83

7 McGahan JP, Rose J, Coates TL, Wisner DH, Newberry P. Use of ultrasonography in the patient with acute abdominal trauma. J Ultrasound Med. 1997;16:653-62.

8 Richards JR, McGahan JP, Simpson JL, Tabar P. Bowel and mesenteric injury: Evaluation with emergency abdominal US Radiol. 1999;211:399-403.

9 Rothlin MA, Naf R, Amgwerd M, Candinas D, Kick T. Ultrasound in blunt abdominal and thoracic trauma. J Trauma. 1993;34:488-495.

10 Luks FI, Lemire A, St-vil D. Blunt abdominal trauma in children: The practical value of ultrasonography. J Trauma. 1993;34 (5):607-10

11 Liu M, Lee CH, P'eng FK. Prospective comparison of diagnostic peritoneal lavage, CT scanning, and ultrasonography for the diagnosis of blunt abdominal trauma. J Trauma. 1993;35(2):267 70 .

12 Huang M, Liu M, Wu J, Shih H, Ko T, Lee C. Ultrasonography for the evaluation of hemoperitoneum during resuscitation: A simple scoring system. J Trauma. 1994;36:173-77.

13 Gruessner R, Mentges B, Duber Ch, Ruckert K, Rothmund M. Ultrasonic and lavage in polytraumatized patients with blunt abdominal trauma. J Trauma. 1989;29(2):242-44.

14 Kimura A, Otsuka T. Emergency centre ultrasonography in the evaluation of hemoperitoneum: A prospective study. J Trauma. 1991;31(1):20-23. 